\title{
Androgen receptor in advanced breast cancer: is it useful to predict the efficacy of anti-estrogen therapy?
}

\author{
Giuseppe Bronte ${ }^{1}$, Andrea Rocca ${ }^{1 *}$, Sara Ravaioli ${ }^{1}$, Maurizio Puccetti ${ }^{2}$, Maria Maddalena Tumedei ${ }^{1}$, \\ Emanuela Scarpi ${ }^{1}$, Daniele Andreis ${ }^{1}$, Roberta Maltoni ${ }^{1}$, Samanta Sarti ${ }^{1}$, Lorenzo Cecconetto ${ }^{1}$, Anna Fedeli ${ }^{1}$, \\ Elisabetta Pietri ${ }^{1}$, Valeria De Simone ${ }^{1}$, Silvia Asioli ${ }^{3}$, Dino Amadori ${ }^{1}$ and Sara Bravaccini ${ }^{{ }^{*}}$
}

\begin{abstract}
Background: Androgen receptor (AR) is widely expressed in breast cancer (BC) but its role in estrogen receptor (ER)-positive tumors is still controversial. The AR/ER ratio has been reported to impact prognosis and response to antiestrogen endocrine therapy (ET).

Methods: We assessed whether AR in primary tumors and/or matched metastases is a predictor of efficacy of first-line ET in advanced BC. Patients who had received first-line ET (2002-2011) were recruited, while those given concomitant chemotherapy or trastuzumab or pretreated with $>2$ lines of chemotherapy were excluded. ER, progesterone receptor (PgR), Ki67 and AR expression were assessed by immunohistochemistry, and HER2 mainly by fluorescent in-situ hybridization. Cut-offs of 1 and 10\% immunostained cells were used to categorize AR expression.

Results: Among 102 evaluable patients, biomarkers were assessed in primary tumors in 70 cases and in metastases in 49, with 17 patients having both determinations. The overall concordance rate between primary tumors and metastases was 64.7\% (95\% Cl 42\%-87.4\%) for AR status. AR status did not affect TTP significantly, whereas PgR and Ki67 status did. $A R / P g R \geq 0.96$ was associated with a significantly shorter $T \mathrm{TP}(H R=1.65,95 \% \mathrm{Cl} 1.05-2.61, p=0.028)$. AR status in primary tumors or metastases was not associated with progressive disease (PD) as best response. In contrast, Ki67 $\geq 20 \%$ and PgR $<10 \%$ showed a statistically significant association with PD as best response.
\end{abstract}

Conclusions: AR expression does not appear to be useful to predict the efficacy of ET in advanced BC, whereas Ki67 and PgR exert a greater impact on its efficacy.

Keywords: Androgen receptor, Advanced breast cancer, Anti-estrogen therapy, Endocrine therapy, AR/ER ratio

\section{Background}

Androgen receptor (AR) is emerging as an important mediator in the biology and therapy of breast cancer (BC). It has a role in breast carcinogenesis, varying on the basis of the expression of other biomarkers, such as estrogen receptor (ER), progesterone receptor (PgR), human epidermal growth factor receptor 2 (HER2/neu), and a prognostic effect has also been observed [1].

\footnotetext{
* Correspondence: andrea.rocca@irst.emr.it; sara.bravaccini@irst.emr.it ${ }^{1}$ Istituto Scientifico Romagnolo per lo Studio e la Cura dei Tumori (IRST) IRCCS, Via P. Maroncelli 40, 47014 Meldola, FC, Italy

Full list of author information is available at the end of the article
}

AR is a nuclear transcription factor, which is activated by the binding of steroid hormone androgens, similarly to other members of this family of receptors including ER and PgR [2].

AR protein is expressed in about $70-90 \%$ of BC. Its levels may however vary depending on the location considered (cytoplasmic and/or nuclear), the cutoff of expression $(\geq 1 \%, \geq 10 \%)$, and the antibody used for immunohistochemistry (IHC) [3, 4].

AR expression in different $\mathrm{BC}$ subtypes is also variable. It is found in about 75\% of ER-positive, $50-60 \%$ of HER2enriched, and $20-40 \%$ of triple negative $\mathrm{BC}$, respectively $[5,6]$. 
Depending on the expression of other hormone receptor proteins and their ligands, the AR pathway may promote or inhibit cell proliferation. Moreover, this interplay between AR, ER and their ligands is complicated by the possible conversion of androgens to estrogens. A cross talk between AR pathway and HER2/neu pathway is also known $[7,8]$.

$A R$ and ER can compete for the binding to estrogen response elements (EREs) on specific genes [9]. So the binding of AR to EREs reduces the estrogen proliferative action, thus inducing anti-proliferative effects. Conversely, ER can bind to androgen response elements (AREs), obtaining the opposite effect [10]. This mechanism could explain the role of AR in the resistance to standard endocrine treatments [11].

Moreover a high AR expression can activate the epidermal growth factor receptor (EGFR), promoting an agonist effect of tamoxifen on ER pathway, and this aberrant mechanism could be blocked by enzalutamide +/- gefitinib [12].

Currently AR is under investigation in the clinical setting as a therapeutic target in BC. Enzalutamide and other anti-androgens appear suitable treatment options for AR-expressing BC [13, 14].

A favorable prognostic role of $\mathrm{AR}$ in $\mathrm{BC}$ was identified in various studies. This effect was confirmed, in terms of both disease-free survival (DFS) and overall survival (OS), in a large meta-analysis including almost 8000 patients with stage I-III BC. In other studies AR expression independently predicted longer $\mathrm{BC}$ specific survival and lower risk of recurrence $[5,15,16]$.

We previously showed the value of PgR and Ki67 to predict benefit from first-line endocrine therapy in a case series of patients with advanced luminal breast cancer [17]. In this study we explore, in the same case series, the prognostic/predictive effect of AR expression.

\section{Methods}

\section{Study design}

A retrospective analysis was performed for this study. Patients with locally advanced or metastatic BC histologically confirmed treated with first-line ET from 2002 to 2011 at Istituto Scientifico Romagnolo per lo Studio e la Cura dei Tumori, IRST (Meldola, Italy), were included. Patients who received concomitant chemotherapy or trastuzumab or pretreated with more than 2 lines of chemotherapy were excluded. All patients were aged $\geq 18$ years and were followed up for a period ranging from 5 to 13 years. We collected data from medical records of these patients. Subsequently we gathered tumor tissue samples of these patients for AR assessment.

The original hematoxylin-eosin stained sections were reviewed by two pathologists responsible for selecting pathological inclusions representative of tumor tissue
Table 1 Patient's characteristics

\begin{tabular}{|c|c|}
\hline No. patients & $102(100)$ \\
\hline Age (years): median value (range) & $60(33-85)$ \\
\hline \multicolumn{2}{|l|}{ Previous adjuvant chemotherapy } \\
\hline No & $37(36.3)$ \\
\hline Yes & $39(38.2)$ \\
\hline Unknown/Not available & $26(25.5)$ \\
\hline \multicolumn{2}{|l|}{ Previous adjuvant endocrine therapy } \\
\hline No & $22(21.6)$ \\
\hline Yes & $54(52.9)$ \\
\hline Unknown/Not available & $26(25.5)$ \\
\hline \multicolumn{2}{|l|}{ Histotype } \\
\hline Ductal & $76(74.5)$ \\
\hline Lobular & $14(13.7)$ \\
\hline Other & $7(6.9)$ \\
\hline Unknown & $5(4.9)$ \\
\hline \multicolumn{2}{|l|}{ Tumor stage } \\
\hline 1 & $30(29.4)$ \\
\hline 2 & $42(41.1)$ \\
\hline 3 & $2(2)$ \\
\hline 4 & $12(11.8)$ \\
\hline Unknown & $16(15.7)$ \\
\hline \multicolumn{2}{|l|}{ Grade of primary tumor } \\
\hline 1 & $2(2)$ \\
\hline 2 & $34(33.3)$ \\
\hline 3 & $32(31.4)$ \\
\hline Unknown & $34(33.3)$ \\
\hline \multicolumn{2}{|l|}{ Nodal involvement } \\
\hline 0 & $24(23.5)$ \\
\hline 1 & $36(35.3)$ \\
\hline 2 & $11(10.8)$ \\
\hline 3 & $11(10.8)$ \\
\hline Unknown & 20 (19.6) \\
\hline \multicolumn{2}{|l|}{ Metastases (at diagnosis) } \\
\hline 0 & $76(74.5)$ \\
\hline 1 & $26(25.5)$ \\
\hline \multicolumn{2}{|l|}{ Type of first-line endocrine therapy } \\
\hline Letrozole & $46(45.1)$ \\
\hline Anastrozole & $22(21.6)$ \\
\hline Exemestane & $26(25.5)$ \\
\hline Tamoxifen & $5(4.9)$ \\
\hline Fulvestrant & $3(2.9)$ \\
\hline
\end{tabular}

and for the analysis of clinical pathological features, such as histologic grade.

The predictive value of AR expression, alone or in relation to the other conventional biomarkers, to select 
the patients responsive to first-line endocrine therapy was the primary endpoint.

IRST and AVR (Area Vasta Romagna) Ethics Committee (approval no. 1164), reviewed and approved the study and informed consent was obtained from all patients.

Data were collected from electronic databases. The following characteristics were evaluated for each single patient.

Patient's data: age at diagnosis. Tumor's data: 1) histotype (ductal, lobular, other, unknown); 2) tumor classification at diagnosis (T1-4, unknown) according to the American Joint Committee on Cancer (AJCC) Cancer Staging Manual 7th Edition; 3) nodal classification (N0-3, unknown); 4) presence of metastases at diagnosis (M0-1); 5) ER, PgR, Ki67, HER2 status in primary tumor and metastasis. Treatments and outcomes: 1) adjuvant chemotherapy; 2) adjuvant ET; 3) type of first-line ET; 4) best objective response (complete response (CR), partial response (PR), stable disease (SD), PD, according to RECIST criteria); 5) time-to-progression (TTP), meant as the time in months from the beginning of first-line ET until progression or last tumor response evaluation available.

All datasets used and/or analyzed during the current study are available from the corresponding author on reasonable request.

\section{Biomarker detection}

Hormone receptors, Ki67, HER2 and AR status of the primary tumor, metastasis or both were assessed for all patients enrolled. The major part (79\%) of the biomarkers detection was performed in the Pathology Unit of Morgagni Pierantoni Hospital in Forlì [17].

Tumor samples obtained during surgery were fixed in neutral buffered formalin and embedded in paraffin. Four-micron sections were mounted on positive-charged slides for each patient (Bio Optica, Milan, Italy). REporting recommendations for tumour MARKer prognostic studies (REMARK) and the European Quality Assurance guidelines were used. Immunostaining for conventional biomarkers and AR expression was performed using the Ventana Benchmark XT staining system (Ventana
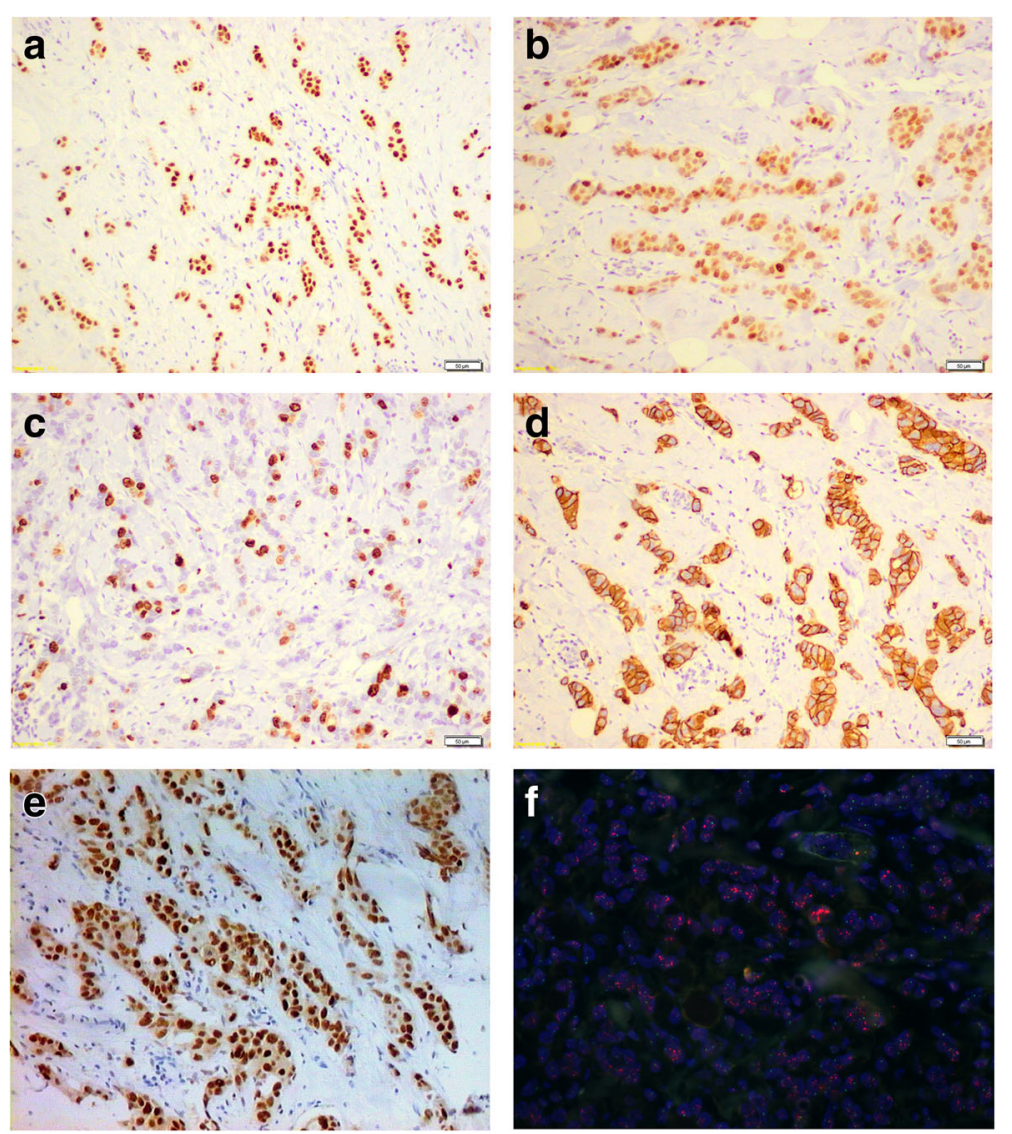

Fig. 1 Biomarkers detection in breast cancer tissue. a ER expression by immunohistochemistry (10X magnification). b PgR expression by immunohistochemistry (10X magnification). c Ki67 expression by immunohistochemistry (10X magnification). d HER2 expression by immunohistochemistry (10X magnification). e AR expression by immunohistochemistry (10X magnification). f HER2 amplified case by Fluorescence in situ hybridization (FISH) (40X magnification) 
Table 2 Biomarkers determination

\begin{tabular}{|c|c|c|c|}
\hline & $\begin{array}{l}\text { Primary tumor } \\
(n=70)\end{array}$ & $\begin{array}{l}\text { Metastases } \\
(n=49)\end{array}$ & $\begin{array}{l}\text { Clinical practice } \\
(n=102)\end{array}$ \\
\hline & No. (\%) & No. (\%) & No. (\%) \\
\hline \multicolumn{4}{|l|}{ ER status } \\
\hline$<1 \%$ & $3(4.3)$ & 0 & $2(2.0)$ \\
\hline$\geq 1 \%$ & 65 (92.9) & $49(100)$ & $100(98.0)$ \\
\hline Unknown & $2(2.8)$ & 0 & 0 \\
\hline \multicolumn{4}{|l|}{ PgR status } \\
\hline$<1 \%$ & $10(14.3)$ & $12(24.5)$ & $22(21.6)$ \\
\hline$\geq 1 \%$ & 58 (82.9) & $37(75.5)$ & $80(78.4)$ \\
\hline Unknown & $2(2.8)$ & 0 & 0 \\
\hline \multicolumn{4}{|l|}{ Ki67 status } \\
\hline$<20 \%$ & 39 (55.7) & $30(61.2)$ & $63(61.8)$ \\
\hline$\geq 20 \%$ & $27(38.6)$ & 17 (34.7) & $38(37.2)$ \\
\hline Unknown & $4(5.7)$ & $2(4.1)$ & $1(1)$ \\
\hline \multicolumn{4}{|l|}{ HER2 status } \\
\hline Negative & 57 (81.4) & 41 (83.7) & $88(86.3)$ \\
\hline Positive & $10(14.3)$ & $7(14.3)$ & $14(13.7)$ \\
\hline Unknown & $3(4.3)$ & $1(2)$ & 0 \\
\hline \multicolumn{4}{|l|}{ AR status } \\
\hline$<1 \%$ & $5(7.1)$ & $12(24.5)$ & $17(16.7)$ \\
\hline$\geq 1 \%$ & 65 (92.9) & $37(75.5)$ & 85 (83.3) \\
\hline$<10 \%$ & $7(10.0)$ & 19 (38.8) & $26(25.5)$ \\
\hline$\geq 10 \%$ & $63(90.0)$ & $30(61.2)$ & $76(74.5)$ \\
\hline
\end{tabular}

Abbreviation: $E R$ estrogen receptor, $P g R$ progesterone receptor, $A R$ androgen receptor, HER2 human epidermal growth factor receptor 2

abiomarker measured on metastatic sample when a metastatic biopsy was available, or on primary tumor when biopsy of metastasis had not been performed
Medical Systems, Tucson, AZ, USA) with the Optiview DAB Detection Kit (Ventana Medical Systems). ER, PgR, Ki67 (Leica, Novocastra, Newcastle, UK), HER2 (Dako, Carpinteria, CA, USA) and AR (SP107 Cell Marque, Ventana Medical Systems) antibodies were used. For ER, PgR, Ki67 and HER2 detection, tissue sections were incubated for 60 min with antibodies diluted 1:80, 1:40, 1: 100 and 1:350, respectively, in antibody diluent (Ventana Medical Systems). The AR antibody was pre-diluted by the supplier. Sections were incubated for $16 \mathrm{~min}$ and automatically counterstained with hematoxylin II (Ventana Medical Systems). Biomarker positivity was detected and semiquantitatively quantified as the percentage between immunopositive tumor cells and the total number of tumor cells. Two independent observers evaluated all the samples and any disagreement was resolved by consensus after joint review using a multihead microscope. Hormone receptors, Ki67 and HER2 biomarkers were classified on the basis of the St. Gallen and ASCO-CAP guidelines [18-20]. In particular tumors were considered ER-positive when $\geq 1 \%$ of immunoreactive cells were detected. The cut-off for PgR positivity was set at $\geq 1 \%$ immunoreactive cells. Ki67 was defined as high when the fraction of positively stained cells was $\geq 20 \%$, and low when $<20 \%$. Fluorescent in situ hybridization, was used preferentially to determine HER2 status and considered positive if the HER2 gene to chromosome 17 centromere ratio was $\geq 2$ or if the average HER2 gene copy number per cell was $\geq 6$. In a minority of cases, HER2 was assessed using the HercepTest (DAKO Corporation) which measures the percentage of immunoreactive neoplastic cells defined according to the intensity and completeness of membrane

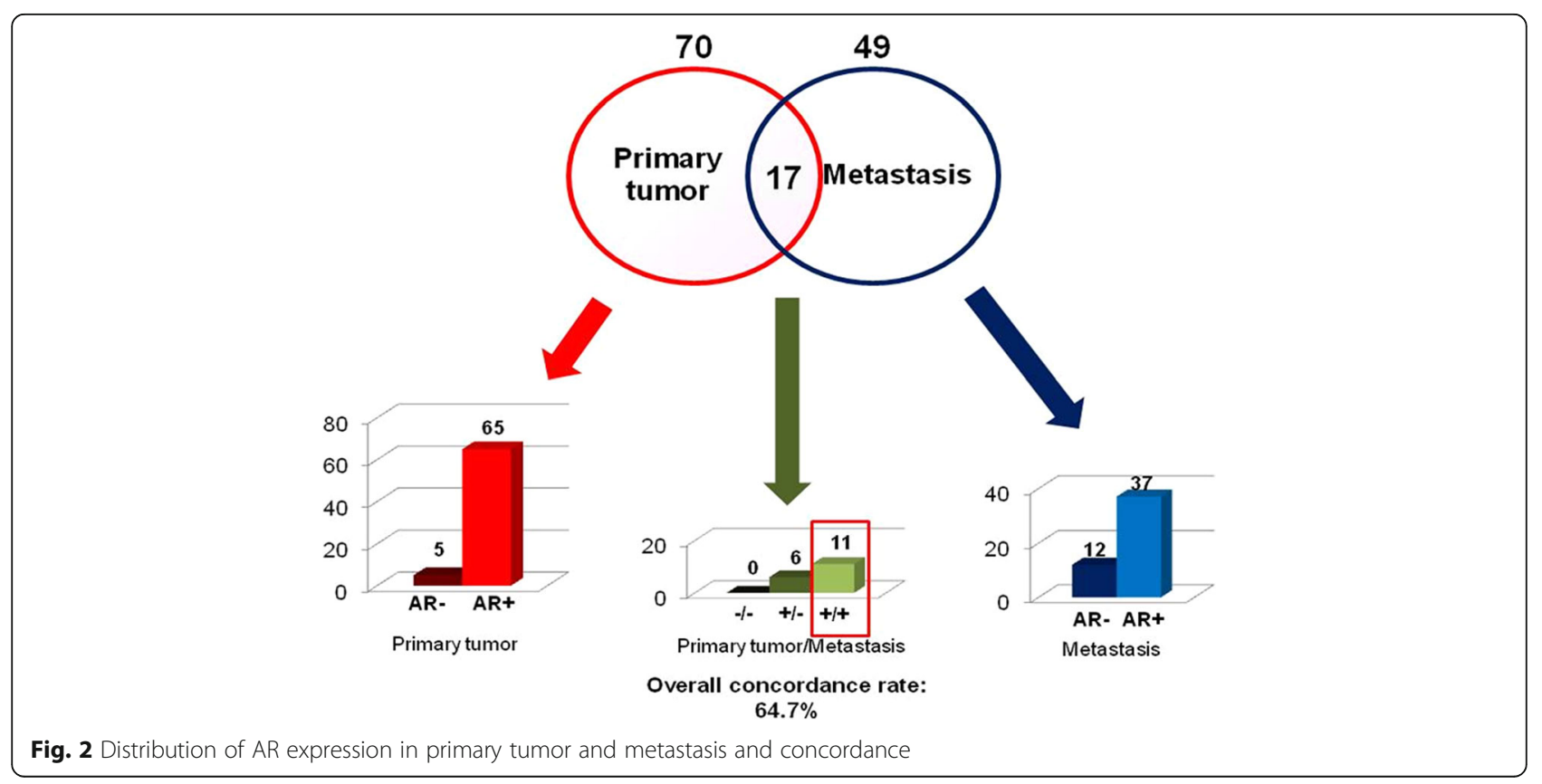


staining and using the $0-3+$ recommended scale. Cases scored as 3+ were considered HER2-positive. In cases of equivocal HER2 immunostaining (2+) FISH was performed [17]. As regards AR expression, tissues showing $\geq 1 \%$ or $\geq 10 \%$ positive tumor cells in their nucleus were defined as positive. The AR/ER and AR/PgR ratios were calculated as the ratio between the percentage of ARpositive tumor cells and the percentage of ER- or PgRpositive tumor cells, respectively.

\section{Statistical analysis}

Patients and tumor features were described according to descriptive statistics.

Positive or negative AR status in both tumor and metastasis was used to define the concordance between tumor and metastasis, while discordance was defined as positivity at one site and negativity at the other one. The concordance rate was calculated as the proportion of concordant cases with respect to the total number of patients. The two-sided exact binomial 95\% confidence interval $(95 \% \mathrm{CI})$ was estimated.

AR expression was analyzed in relation to the other conventional biomarkers (ER, PgR, HER2 and Ki67), best response to therapy $(\mathrm{CR}, \mathrm{PR}, \mathrm{SD}, \mathrm{PD})$, and time to progression (TTP) (months). Kaplan-Meier method was used to estimate TTP and compared with the logrank test. Hazard ratios (HR) and their 95\% CI were calculated using the Cox regression model.

The Chi Square test was used to evaluate the association between categorical variables and best response and the non-parametric ranking test (Wilcoxon test) was used to evaluate the relationship between median value of AR expression and Ki67 classes $(<20 \%, \geq 20 \%)$.

To determine the optimal cutoff values of AR/ER and $\mathrm{AR} / \mathrm{PgR}$ ratios at a median TTP time Receiver operating characteristic (ROC) curves were used.

Analyses were performed using SAS Statistical software (version 9.4, SAS Institute, Cary, North Carolina, USA). Statistical tests were significant for $p$ values $<0.05$.

\section{Results}

\section{Patients' characteristics}

One hundred and two patients were evaluable according to the selection criteria and the availability of tissue samples. Median age was 60 years (range 33-85). Seventy eight percent of them were diagnosed as ductal and $14 \%$ as lobular histotype. Metastatic disease at diagnosis was found in 26 out of 102 (25.5\%). Ninety two percent were treated with an aromatase inhibitor as first-line endocrine therapy, and letrozole was the most frequent aromatase inhibitor administered (45\%). For detailed description of patients' characteristics see Table 1.

\section{Biomarkers' distribution}

Biomarker's expression (ER, PgR, Ki67, HER2 and AR) was assessed in primary tumors in 70 cases and in metastases in 49 , with 17 patients having both assessments (Fig. 1a-f) (Table 2).

ER was negative $(<1 \%)$ in 3 samples $(4.3 \%)$ of primary tumors and in none of the metastatic samples. PgR was negative $(<1 \%)$ in $10(14.3 \%)$ primary tumors and in 12 $(24.5 \%)$ metastases. Ki67 was low $(<20 \%)$ in $59.1 \%$ of primary tumors and in $61.2 \%$ of metastases. HER 2 status was positive in about $15 \%$ of cases both in primary tumors and metastases. In Fig. 1f, a HER2 FISH amplified case has been reported.

AR status (Fig. 1e), considered as per clinical practice (biomarker measured on a metastatic sample when a metastatic biopsy is available, or measured on primary tumor when biopsy of a metastasis has not been performed), was negative in 17 (16.7\%) cases with cutoff $<1 \%$

Table 3 Response to treatment in relation to biomarkers expression considered as per clinical practice ${ }^{a}$

\begin{tabular}{|c|c|c|c|c|}
\hline & \multirow[t]{2}{*}{ No. } & \multirow{2}{*}{$\begin{array}{l}\text { CR or PR or SD } \\
\text { No. }(\%)\end{array}$} & PD & \multirow[t]{2}{*}{$p$} \\
\hline & & & No. (\%) & \\
\hline \multicolumn{5}{|l|}{ ER status } \\
\hline$<1 \%$ & 1 & 0 & $1(100)$ & \\
\hline$\geq 1 \%$ & 72 & $64(88.9)$ & $8(11.1)$ & 0.123 \\
\hline \multicolumn{5}{|l|}{ PgR status } \\
\hline$<1 \%$ & 15 & $11(73.3)$ & $4(26.7)$ & \\
\hline$\geq 1 \%$ & 58 & $53(91.4)$ & $5(8.6)$ & 0.079 \\
\hline \multicolumn{5}{|l|}{ Ki67 status } \\
\hline$<20 \%$ & 46 & $44(95.7)$ & $2(4.3)$ & \\
\hline$\geq 20 \%$ & 26 & $19(73.1)$ & $7(26.9)$ & 0.009 \\
\hline \multicolumn{5}{|l|}{ HER2 status } \\
\hline Negative & 64 & $57(89.1)$ & $7(10.9)$ & \\
\hline Positive & 9 & $7(77.8)$ & $2(22.2)$ & 0.306 \\
\hline \multicolumn{5}{|l|}{ AR status } \\
\hline$<1 \%$ & 12 & $10(83.3)$ & $2(16.7)$ & \\
\hline$\geq 1 \%$ & 61 & $54(88.5)$ & $7(11.5)$ & 0.619 \\
\hline$<10 \%$ & 19 & $15(79.0)$ & $4(21.0)$ & \\
\hline$\geq 10 \%$ & 54 & $49(90.7)$ & $5(9.3)$ & 0.182 \\
\hline \multicolumn{5}{|l|}{ AR/ER ratio } \\
\hline$<0.90$ (best cutoff) & 38 & $31(81.6)$ & $7(18.4)$ & \\
\hline$\geq 0.90$ (best cutoff) & 35 & $33(94.3)$ & $2(5.7)$ & 0.101 \\
\hline \multicolumn{5}{|l|}{ AR/PgR ratio } \\
\hline$<0.96$ (best cutoff) & 27 & $23(85.2)$ & $4(14.8)$ & \\
\hline$\geq 0.96$ (best cutoff) & 46 & $41(89.1)$ & $5(10.9)$ & 0.623 \\
\hline
\end{tabular}

Abbreviations: $C R$ complete response, $P R$ partial response, $S D$ stable disease, $P D$ progressive disease, $E R$ estrogen receptor, $P g R$ progesterone receptor, $A R$ androgen receptor, HER2 human epidermal growth factor receptor 2 abiomarker measured on metastatic sample when a metastatic biopsy was available, or on primary tumor when biopsy of metastasis had not been performed 
and $26(25.5 \%)$ cases with cutoff $<10 \%$. The overall concordance rate between primary tumors and metastases was $64.7 \%$ (95\% CI $42.0 \%-87.4 \%$ ) for AR expression, based on cutoff of $1 \%$ (Fig. 2). Furthermore we observed a statistically significant association of AR status with a low Ki67, with median value of AR expression as per clinical practice of $80 \%$ in patients with Ki67 $<20 \%$ versus $70 \%$ in patients with ki67 $\geq 20 \%(p=0.017)$.

\section{Outcome measures}

AR status in primary tumors or metastases was not associated with PD as best response (Table 3).

Clinical benefit rate, defined as CR or PR or SD, was 88.5\% and PD 11.5\% for AR-positive tumors defined by a cutoff $\geq 1 \%$, versus $83.3 \%$ and $16.7 \%$, respectively, for AR-negative tumors $(p=0.62)$; clinical benefit was $90.7 \%$ and PD 9.3\% for AR-positive tumors defined by a cutoff $\geq 10 \%$, versus $79 \%$ and $21 \%$, respectively, for AR-negative tumors $(p=0.18)$. Conversely Ki67 showed a significant association with PD as best response, with 26.9\% PD with high Ki67 versus 4.3\% PD with low Ki67 $(p=0$. 009). PgR-negative status defined by a cutoff $<1 \%$ showed just a trend in terms of association with PD as best response $(p=0.079)$, while significant results $(p=0$. 031 ) were obtained by using $\leq 10 \% \operatorname{PgR}$ as cut off value.
Median TTP was 17 months (95\% CI 14-21.5, median follow-up 75 months). Differences in TTP according to AR status were not statistically significant (Table 4). For AR expression $\geq 1 \%$ median TTP was 16.1 months (95\% CI 13.0-19.0), versus 12 months (95\% CI 4.3-48.1) for AR < $1 \%(p=0.884)$; similarly for AR $\geq 10 \%$ median TTP was 16 months (95\% CI 13.0-19.0) vs 13.8 months (95\% CI 11.0-42. $1)$ for $\mathrm{AR}<10 \%(p=0.935)$. $\mathrm{AR} / \mathrm{PgR} \geq 0.96$ was associated with a significantly shorter TTP $(H R=1.65$, 95\% CI 1.05-2.61, $p=0.028$ ) (Fig. 3). No associationwas found between AR/ER ratio and TTP. Conversely, a positive PgR status and a low Ki67 (but not HER2 status) were significantly associated with longer TTP (Table 4).

\section{Discussion}

Most of ER-positive BCs are AR-positive (about 80-90\% of them) and the coexpression of AR, ER and PgR is associated with a better prognosis and well-differentiated phenotype [21-23].

Some studies suggest that the levels of expression of $A R$ and its relation to ER expression levels in primary tumors predict benefit from adjuvant endocrine therapy with tamoxifen [11].

Table 4 Time to progression (TTP) according to biomarkers expression considered as per clinical practice

\begin{tabular}{|c|c|c|c|c|}
\hline & No. & $\mathrm{HR}(95 \% \mathrm{Cl})^{\mathrm{b}}$ & Median TTP, months (95\% CI) & $p$ \\
\hline \multicolumn{5}{|l|}{ AR status } \\
\hline$<1 \%$ & 17 & 1.00 & $12.0(4.3-48.1)$ & \\
\hline$\geq 1 \%$ & 85 & $0.96(0.56-1.66)$ & $16.1(13.0-19.0)$ & 0.884 \\
\hline$<10 \%$ & 26 & 1.00 & $13.8(11.0-42.1)$ & \\
\hline$\geq 10 \%$ & 76 & $0.98(0.61-1.57)$ & $16.0(13.0-19.0)$ & 0.935 \\
\hline \multicolumn{5}{|l|}{ AR/ER ratio } \\
\hline$<0.90$ (best cutoff) & 52 & 1.00 & $12.9(11.0-17.1)$ & \\
\hline$\geq 0.90$ (best cutoff) & 50 & $0.83(0.55-1.24)$ & $18.0(14.0-24.6)$ & 0.362 \\
\hline \multicolumn{5}{|l|}{ AR/PgR ratio } \\
\hline$<0.96$ (best cutoff) & 34 & 1.00 & $16.8(12.1-47.9)$ & \\
\hline$\geq 0.96$ (best cutoff) & 68 & $1.65(1.05-2.61)$ & $16.0(12.4-19.0)$ & 0.028 \\
\hline \multicolumn{5}{|l|}{ PgR status } \\
\hline$<1 \%$ & 22 & 1.00 & $10.5(4.0-17.0)$ & \\
\hline$\geq 1 \%$ & 80 & $2.18(1.34-3.55)$ & $17.0(14.0-24.7)$ & 0.001 \\
\hline \multicolumn{5}{|l|}{ Ki67 status } \\
\hline$<20 \%$ & 63 & 1.00 & $17.6(14.8-22.1)$ & \\
\hline$\geq 20 \%$ & 38 & $1.60(1.05-2.45)$ & $12.0(8.2-16.1)$ & 0.028 \\
\hline \multicolumn{5}{|l|}{ HER2 status } \\
\hline negative & 88 & 1.00 & $15.8(12.9-19.0)$ & \\
\hline positive & 14 & $1.15(0.65-2.02)$ & $18.0(7.0-46.0)$ & 0.929 \\
\hline
\end{tabular}

Abbreviations: $E R$ estrogen receptor, $P g R$ progesterone receptor, $A R$ androgen receptor, $H E R 2$ human epidermal growth factor receptor 2

abiomarker measured on metastatic sample when a metastatic biopsy was available, or on primary tumor when biopsy of metastasis had not been performed

${ }^{\mathrm{b}} \mathrm{HR}$ hazard ratio 


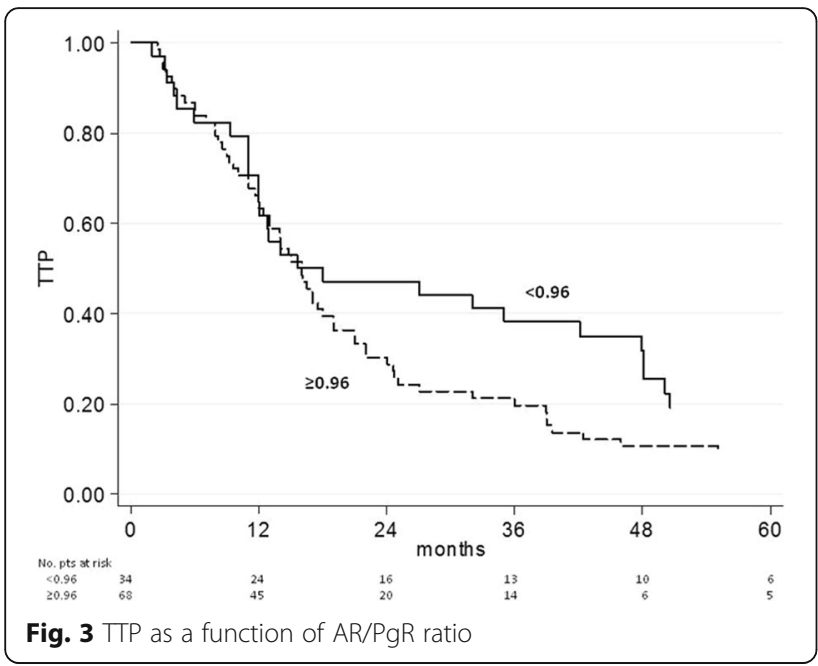

This study was not powered to determine whether AR expression could predict response to tamoxifen or fulvestrant, as the majority of patients received aromatase inhibitors and very few patients received those therapies.

Nevertheless our findings suggest that AR expression does not predict the efficacy of first-line endocrine treatment (mainly based on aromatase inhibitors in our study) in ER- or PgR-positive advanced BC, both in term of TTP and PD as best response.

These results might be influenced by the limited amount of AR negative cases in this subtype of $\mathrm{BC}$. Moreover, the stronger predictive effect of PgR and Ki67 could make the role of AR expression less evident, as suggested by the predictive significance of the AR/ PgR ratio.

Cochrane et al. [11]. evaluated nuclear protein expression levels of AR and ER because previous studies reported that AR mRNA and protein decrease in tumors responsive to neoadjuvant endocrine therapy $[24,25]$. The best cutoff point for AR/ER ratio was 2.0 as determined by ROC analysis in the study by Cochrane et al. We evaluated, for the first time, both AR/ER ratio and AR/PgR ratio in a subset of metastatic $\mathrm{BC}$ patients, to assess their predictive potential for efficacy of endocrine therapy. These ratios were measured as the percentages of tumor positive cells for each receptor, through immunohistochemical staining. In our study, the ROC analysis identified 0.9 as the best cut-off value for AR/ER ratio, which differed from the one calculated by Cochrane et al. probably due to the different subset of patients analyzed, and was not associated with outcome.

Moreover we evaluated AR/PgR ratio and we found a potential predictive value of this parameter at the cut-off of 0.96 . This finding could be explained by the stronger predictive value of $\mathrm{PgR}$ alone in comparison with $\mathrm{AR}$ alone, as $\mathrm{PgR}<10 \%$ and $\mathrm{Ki} 67 \geq 20 \%$ showed a significant association with $\mathrm{PD}$ as best response, and $\operatorname{PgR} \leq 1 \%$ and $\mathrm{Ki} 67 \geq 20 \%$ were significantly associated with shorter TTP.

\section{Conclusions}

PgR and Ki67 seem to be useful to select patients with a higher probability of being responsive to first-line endocrine therapy for metastatic $\mathrm{BC}$, whereas $\mathrm{AR}$ expression does not appear to be useful. The AR expression could acquire more relevance when anti-androgen therapy will be available for $\mathrm{BC}$ patients.

\begin{abstract}
Abbreviations
AR: Androgen receptor; ARE: Androgen response element; BC: Breast cancer; CR: Complete response; DFS: Disease-free survival; EGFR: Epidermal growth factor receptor; ER: Estrogen receptor; ERE: Estrogen response element; ET: Endocrine therapy; HER2/neu: Human epidermal growth factor receptor 2; HR: Hazard ratio; IHC: Immunohistochemistry; OS: Overall survival; PD: Progressive disease; PgR: Progesterone receptor; PR: Partial response; ROC: Receiver operating characteristic; SD: Stable disease; TTP: Time to progression
\end{abstract}

\section{Acknowledgments}

The authors thank Cristiano Verna and Gráinne Tierney for editorial assistance.

\section{Funding}

No funding to declare.

\section{Availability of data and materials}

All datasets used and/or analyzed during the current study are available from the corresponding authors on reasonable request.

\section{Authors' contributions}

GB and SB conceived the idea for the study and drafted the manuscript. RM, SS, LC, AF, EP, VDS and SA collected the clinical data. SR and MMT performed the experimental analyses. MP read the $\mathrm{HC}$ stained specimens. ES and Da-An performed the statistical analysis. AR and Di-Am revised the manuscript for important intellectual content. All the authors read and approved the final manuscript.

\section{Ethics approval and consent to participate}

All procedures performed in studies involving human participants were in accordance with the ethical standards of the institutional research committees and with the 1964 Helsinki declaration and its later amendments or comparable ethical standards. The study protocol was reviewed and approved by the IRST and AVR (Area Vasta Romagna) Ethics Committee (approval no. 1164), and informed consent was obtained from all individual participants included in the study.

Consent for publication

Not applicable.

Competing interests

The authors declare that they have no competing interests.

\section{Publisher's Note}

Springer Nature remains neutral with regard to jurisdictional claims in published maps and institutional affiliations.

\section{Author details}

${ }^{1}$ Istituto Scientifico Romagnolo per lo Studio e la Cura dei Tumori (IRST) IRCCS, Via P. Maroncelli 40, 47014 Meldola, FC, Italy. ${ }^{2}$ S. Maria delle Croci Hospital, 48121 Ravenna, Italy. ${ }^{3}$ Department of Pathology,

Morgagni-Pierantoni Hospital, 47121 Forlì, Italy. 
Received: 29 November 2017 Accepted: 16 March 2018

Published online: 27 March 2018

\section{References}

1. Pietri E, Conteduca V, Andreis D, Massa I, Melegari E, Sarti S, et al. Androgen receptor signaling pathways as a target for breast cancer treatment. Endocr Relat Cancer. 2016:23:485-98.

2. Quigley CA, De Bellis A, Marschke KB, el-Awady MK, Wilson EM, French FS. Androgen receptor defects: historical, clinical, and molecular perspectives. Review. Endocr Rev. 1995;16:271-321.

3. Moinfar F, Okcu M, Tsybrovskyy O, Lax SF, Weybora W, Ratschek M, et al. Androgen receptors frequently are expressed in breast carcinomas: potential relevance to new therapeutic strategies. Cancer. 2003:98:703-11.

4. Collins LC, Cole KS, Marotti JD, Hu R, Schnitt SJ, Tamimi RM. Androgen receptor expression in breast cancer in relation to molecular phenotype: results from the Nurses' Health Study. Mod Pathol. 2011;24:924-31.

5. Vera-Badillo FE, Empleton AJ, de Gouveia P, Diaz-Padilla I, Bedard PL, AlMubarak M, et al. Androgen receptor expression and outcomes in early breast cancer: a systematic review and meta-analysis. J Natl Cancer Inst. 2014;106:djt319.

6. McGhan LJ, McCullough AE, Protheroe CA, Dueck AC, Lee JJ, Nunez-Nateras $R$, et al. Androgen receptor-positive triple negative breast cancer: a unique breast cancer subtype. Ann Surg Oncol. 2014;21:361-7.

7. Need EF, Selth LA, Harris TJ, Tilley WD, Buchanan G. Research resource: interplay between the genomic and transcriptional networks of androgen receptor and estrogen receptor a in luminal breast cancer cells. Mo Endocrinol. 2012;26:1941-52

8. Naderi A, Hughes-Davies L. A functionally significant cross-talk between androgen receptor and ErbB2 pathways in estrogen receptor negative breast cancer. Neoplasia. 2008;10:542-8.

9. Peters AA, Buchanan G, Ricciardelli C, Bianco-Miotto T, Centenera MM, Harris $J M$, et al. Androgen receptor inhibits estrogen receptor-alpha activity and is prognostic in breast cancer. Cancer Res. 2009;69:6131-40.

10. Rechoum Y, Rovito D, lacopetta D, Barone I, Andò S, Weigel NL, et al. AR collaborates with ERa in aromatase inhibitor-resistant breast cancer. Breast Cancer Res Treat. 2014;147:473-85.

11. Cochrane DR, Bernales S, Jacobsen BM, Cittelly DM, Howe EN, D'Amato NC, et al. Role of the androgen receptor in breast cancer and preclinical analysis of enzalutamide. Breast Cancer Res. 2014;16:R7.

12. Ciupek A, Rechoum Y, Gu G, Gelsomino L, Beyer AR, Brusco L, et al. Androgen receptor promotes tamoxifen agonist activity by activation of EGFR in ERapositive breast cancer. Breast Cancer Res Treat. 2015;154:225-37.

13. Gucalp A, Tolaney S, Isakoff SJ, Ingle JN, Liu MC, Carey LA, et al. Phase II trial of bicalutamide in patients with androgen receptor-positive, estrogen receptornegative metastatic breast cancer. Clin Cancer Res. 2013;19:5505-12.

14. Traina TA, Miller K, Yardley DA, O'Shaughnessy J, Cortes J, Awada A, et al. Results from a phase 2 study of enzalutamide (ENZA), an androgen receptor (AR) inhibitor, in advanced AR+ triple-negative breast cancer (TNBC). Abstract J Clin Oncol. 2015;33:1003

15. Qu Q, Mao Y, Fei XC, Shen KW. The impact of androgen receptor expression on breast cancer survival: a retrospective study and meta-analysis. PLoS One. 2013;8:e82650.

16. Aleskandarany MA, Abduljabbar R, Ashankyty I, Elmouna A, Jerjees D, Ali S, et al. Prognostic significance of androgen receptor expression in invasive breast cancer: transcriptomic and protein expression analysis. Breast Cancer Res Treat. 2016:159:215-27.

17. Rocca A, Farolfi A, Maltoni R, Carretta E, Melegari E, Ferrario C, et al. Efficacy of endocrine therapy in relation to progesterone receptor and Ki67 expression in advanced breast cancer. Breast Cancer Res Treat. 2015;152:57-65.

18. Goldhirsch A, Winer EP, Coates AS, Gelber RD, Piccart-Gebhart M, Thürlimann $B$, et al. Personalizing the treatment of women with early breast cancer: highlights of the St Gallen International Expert Consensus on the Primary Therapy of Early Breast Cancer 2013. Ann Oncol. 2013:24:2206-23.

19. Wolff AC, Hammond ME, Hicks DG, Dowsett M, MCShane LM, Allison KH, et al. Recommendations for human epidermal growth factor receptor 2 testing in breast cancer: American Society of Clinical Oncology/College of American Pathologists clinical practice guideline update. J Clin Oncol. 2013; 31:3997-4013

20. Hammond ME, Hayes DF, Dowsett M, Allred DC, Hagerty KL, Badve S, et al. American Society of Clinical Oncology/College Of American Pathologists guideline recommendations for immunohistochemical testing of estrogen and progesterone receptors in breast cancer. J Clin Oncol. 2010;28:2784-95.

21. Hu R, Dawood S, Holmes MD, Collins LC, Schnitt SJ, Cole K, et al. Androgen receptor expression and breast cancer survival in postmenopausal women. Clin Cancer Res. 2011;17:1867-74.

22. Kuenen-Boumeester $\mathrm{V}$, Van der Kwast TH, Claassen CC, Look MP, Liem GS, Klijn JG, et al. The clinical significance of androgen receptors in breast cancer and their relation to histological and cell biological parameters. Eur J Cancer. 1996:32A:1560-5.

23. Søreide JA, Lea OA, Varhaug JE, Skarstein A, Kvinnsland S. Androgen receptors in operable breast cancer: relation to other steroid hormone receptors, correlations to prognostic factors and predictive value for effect of adjuvant tamoxifen treatment. Eur J Surg Oncol. 1992;18:112-8.

24. Harvell DM, Spoelstra NS, Singh M, McManaman JL, Finlayson C, Phang T, et al. Molecular signatures of neoadjuvant endocrine therapy for breast cancer: characteristics of response or intrinsic resistance. Breast Cancer Res Treat. 2008;112:475-88.

25. Harvell DM, Richer JK, Singh M, Spoelstra N, Finlayson C, Borges VF, et al. Estrogen regulated gene expression in response to neoadjuvant endocrine therapy of breast cancers: tamoxifen agonist effects dominate in the presence of an aromatase inhibitor. Breast Cancer Res Treat. 2008;112:489-501.

\section{Submit your next manuscript to BioMed Central and we will help you at every step:}

- We accept pre-submission inquiries

- Our selector tool helps you to find the most relevant journal

- We provide round the clock customer support

- Convenient online submission

- Thorough peer review

- Inclusion in PubMed and all major indexing services

- Maximum visibility for your research

Submit your manuscript at www.biomedcentral.com/submit
Biomed Central 